\title{
Metathesis Phonological Process in Kalhori Kurdish within Optimality Theory
}

\section{Ghader AllahweisiAzar ${ }^{1}$}

Received: Jan09, 2018

\author{
Amin Rahimi Nejad ${ }^{2}$
}

Reviewed: Mar 22, 2018
Accepted: Mar31, 2018

\section{Abstract

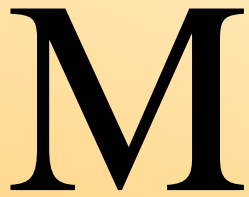

etathesis is one of the phonological processes that serves the phonotactic rules of the language to improve the phonological structures of the language. Marked structures are not regularly preferred in the languages, so, in trying to force the marked structures of the language toward nonmarkedness, phonotactic rules of the language also monitor all the structures that enter the language and change the dispreferred structures in accordance with the universal principles and especially languages parameter. This paper explained the diachronic performance of metathesis process in Kalhori Kurdish. Four different kinds of this process have been investigated, three of them have been explained based on the Optimality Theory approach, and the last one has been presented and described, but a thorough explanation will require more time and studies to the rareness of the samples of its occurrence and consequently poorness of the understanding and generalizations, which can be drawn from them.

Keywords: Metathesis, Kalhori Kurdish, Optimality Theory, Phonology, Phonotactics

\section{Recommended citation:}

AllahweisiAzar G. \& Nejad A. R. (2018). Metathesis phonological process in Kalhori Kurdish within Optimality Theory. International Journal of Kurdish Studies 4 (2), 322-335.

doi: 10.21600/ijoks.454447

\footnotetext{
${ }^{1} \mathrm{PhD}$ Student of General Linguistics in Sanandaj Azad University. E-mail:esirwan@gmail.com

${ }^{2}$ M.A in General Linguistics, Tehran Payam Noor University. E-mail:aasurewar@gmail.com
} 


\section{INTRODUCTION}

Metathesis is a phonological process in which the expected linear sequence of segments in a syllable or two adjacent or non-adjacent syllables switches. These segments can be two consonants, a consonant and a vowel or two vowels. Also there is another kind of it, in which two nonadjacent consonants from initial and final positions of a syllable change their positions without changing their articulatory features. Based on the distance of metathesized segments, the various kinds of it has been grouped in two types: "Metathesis can be contiguous, that is the consonants [segments] that undergo metathesis are in contact without any vowel [other segment] between them, or non-contiguous Metathesis that is the consonants [segments] are separated by a vowel [another segment] (Leslau, 1992: 97). It should be add that in some cases of non-contiguous metathesis the segments that undergo the process belong to two nonadjacent syllables. Consider an imaginary example: in a given word of $\left[\mathrm{C}_{1} \mathrm{VC}_{2} \cdot \mathrm{C}_{3} \mathrm{VC}_{4} \cdot \mathrm{C}_{5} \mathrm{VC}_{6}\right], \mathrm{C}_{2}$ and $\mathrm{C}_{5}$ switch their places $\left[\mathrm{C}_{1} \mathrm{~V}_{\underline{5}} \cdot \mathrm{C}_{3} \mathrm{VC}_{4} \cdot \underline{\mathrm{C}_{2}} \mathrm{VC}_{6}\right]$. In this case two segments from two nonadjacent syllables (which another syllable located between them) undergo the process.

Like many other phonological processes, metathesis can be investigated diachronically but also synchronically. Rules of phonological metathesis could rarely been employed especially in synchronic linguistics, because the samples of it are commonly irregular. Powell (1985: 106) believed "sporadic and irregular, examples of metathesis are often treated as if labeling it were explaining it". Some linguists consider it as a kind of speech error. Therefore Spincer (1996:68) noticed that metathesis is a regular speech error and also "a common feature of child phonology". Even though synchronical metathesis sometimes has been regarded as a poorly understood process, it has been "well recognized in historical linguistics [...] but they can also be seen in performance errors, in tongue slips [...] or in the performance of spoonerism" (Crystal, 1997: 240).

In contrast, many of linguists and scholars define Metathesis as a phonological process. "Chomsky and Halle (1968: 361) describe metathesis as a'a perfectly common phonological process"' (Oostendrop, 2011: 1381). "The phonological process that reorders sounds within words, often making them easier to pronounce is called metathesis" (Fingan, 2014:140). Also Paul and others (2013: 12) defined metathesis as a phonological process that typically affects segments in proximity.

However this process is common less than other phonological processes, but like many others, the outcome of this process is a simpler phonological structure, and also it is believed that it is motivated completely phonologically. Ahmadkhani (2010: 6) pointed out that "this process is indeed less natural phonetically than other processes, and has a relatively greater phonological motivation". "Metathesis appears to be only phonological. [...] Although metathesis has no grammatical function [...], scholars often take the view that it has at least an incidental function an a phonological level" (Hickey, 2014: 2010). Metathesis totally 
produces better and easier structures (whether it is a kind of slip of the tongue, error, spoonerism or is occurred as a real phonological process) and causes a kind of concordance between a special phonological structure and the phonetic system of the language, this argument is an important one in this paper that will be more discussed in following sections.

It seems that one of the main reasons of this process is the presence of a harder segments chain to produce, and naturally phonotactic rules of the phonology seek to find a better and easier arrangement, therefore they suggest a segment shift. "Metathesis arises when 'the order of sounds and the syllable boundary make for inconvenience': it causes a group of sounds [to be] placed where it is easier for the speaker" (Brugmann, 1902: 246) ${ }^{3}$. Uffiman (2007: 30) demonstrated it through markedness concept: "Metathesis occurs not because there is a constraint METATHESIZES but because markedness considerations might enforce it, despite the existence of an anti-metathesis constraint LINEARITY". One of the main approaches for discussing and explaining the phonological process of metathesis is Sonority Sequencing Principle (SSP). This principle argues that the best ordering of segments within the borders of syllable is according to the level of sonority of the segments. "the Sonority Sequencing Principle is a rule that governs the way in which consonants are combined within syllables" (Pascoe, 2006: 119). Selkirk (1984: 116) defines SSP in this way:

"In any syllable there is segment constituting a sonority peak that is preceded and or followed by a sequence of segments with progressively decreasing sonority values".

Following hierarchy shows the level of sonority of natural sound classes which has been suggested by many linguists like: Clements (1990: 286), Uchihara (2016: 56), Cruttenden (2014: 50-51):

$$
\text { stop }<\text { fricative }<\text { nasal }<\text { liquid }<\text { glide }<\text { vowel }
$$

therefore, according to the SSP the preferable arrangement of the segments in syllable, based on their sonority level, must be as following format:

\section{stop $<$ fricative $<$ nasal $<$ liquid $<$ glide $<\underline{\text { vowel }}>$ glide $>$ liquid $>$ nasal $>$ fricative $>$ stop ONSET NUCLUS CODA}

So, the more sonorant is a segment, the closer position to the nucleus can possess, this is the preferred and ideal sequence of syllable segments. And also syllable contact law is been formulated by Clement (1990: 287) as bellow:

In any sequence $C_{a} \# C_{b}$, there is preference for $C_{a}$ to exceed $C_{b}$ in sonority.

\footnotetext{
${ }^{3}$ Cited from; (1998; 508),Language, Volume 74, Issues 3-4, Linguistic Society of America
} 
Also Ball and others (2014: 22) recited from Clements (1990):

"Syllable maximally rise in sonority from the onset to the nucleus. [...] but syllable codas do not share this preference for a sharp change in sonority, [...] there is a greater preference for codas that fall less sharply."

From this principle which has been recited by many linguists, it could be concluded that the onset of the syllable tends to be less sonorous than the coda. It can be a strategy to fulfill the syllable law contact, which states that the coda is more sonorant than the onset of the next syllable.

So any segment sequencing that violates SSP principle and all its laws, can be a suitable candidate to be rearranged. Every language regularly uses its own strategy to cope with the violations. Phonological process of deletion, lenition and of course metathesis and some others are among the choices of phonotactic rules of the language to optimize the illformed sequences.

This paper intends to investigate metathesis in Kalhori dialect of Kurdish through the framework of Optimality Theory. Almost all instances of metathesis in this geographical variety of Kurdish language are among loanwords that have entered this dialect at least in recent centuries. Though metathesis also can serve morphological purposes in some languages (Gordon, 2016, 170) and consequently can be discussed morphologically, in this paper, it will be investigated just in special cases which is necessary for the mentioned language.

\section{Optimality Theory}

Optimality theory which is referred to as 'constraint based approach' is a theory that was presented by Prince and Smolensky. They have formulated this theory as a response to the "conceptual crisis at the center of phonological thought" (prince \& Smolensky, 1993: 1). "Optimality Theory (OT) explores the idea that universal grammar consists of representational well-formedness constraints from which individual languages are constructed" (Damper, 2012: 55). This theory is simpler and easier than Generative theory. In this approach analyzing, describing and explaining of generalizations is based on the markedness phenomenon which has been introduced for the first time by Trobzkoy in the Prague School, and now "with the emergence of Optimality Theory (OT), again, as a focal point it has received more attention" (Bijankhan, 2009, 17). Even though MacCarthy (2002: 15) believed that: "the technical sense of markedness, as used in OT, is distinct from and a good deal more specific than the more familiar usage of this word in linguistics, dating back to the Prague school in 1930". Reciting the Keans definition of markedness in older usage as a concept to distinct between neutral, natural and most expected forms as unmarked from what is not neutral as unmarked (from Kean, 1992: 390), MacCarthy (2002: 15) pointed out that "a markedness constraint in OT may produce results related to this descriptive or 
typological sense of markedness, but the formal constraint and typological observation are two different things".

There are an input and an output in OT, which are roughly equivalent the underlying representation and surface form in Generative phonology respectively. There is a strong relation between input and output which is controlled and monitored by a group of specific rules. The framework of this theory is totally composed of following components and concepts: Input, Generator, Evaluator, Candidates, Constraints and Output. These elements will be briefly defined:

Input: is a term in OT, which its meaning is to some extent different from its general use in linguistics. "An input is at linguistic construct, composed from the elements in Universal Grammar (consonant, vowel, syllable, noun, verb, etc.) to which output representation are related" (Crystal, 2008: 247). This input which originated from Universal Grammar enters the first component of OT, Generator.

Generator: [hereafter GEN] is a functional component which generates all the possible forms of input as a candidate set of output. In fact the relation between input and output is generated by this component.

Candidate: [hereafter $\mathrm{CAN}$ ] is a primary possible or potential form of output that has been produced by the generator component. The candidate which has the fewest number of violations from the predetermined constraints will be chosen by evaluator as output form.

Constraint: [hereafter $\mathrm{CON}$ ] is in fact the "principle explanatory device" in OT [which they are] "ways of characterizing language universals" (Crystal, 2008: 106). There are two types of CONs: markedness CONs which they "reflect typological generalizations about segments and features in the worlds languages" (Miglio, 2013: 10). This kind of CON totally tend to force all the language forms toward the unmarked representations and prevent of markedness presentations to be produced.

"as a matter of fact markedness in OT corresponds to the presence of mark with respect to a given constraint (defined as harmony). A form is therefore said to be marked with respect to some constraints $\mathrm{C}$ if it violate it and hence receives a mark. The form is unmarked with respect to that constraint if it does not violate it and therefore does not receive any marks." (Fery and Vijver, 2003: 360)

In contrary, faithfulness CONs totally are against any change from input to output, it means they penalize changes and differences between input and output. But it should be noted that both kind of the CONs can be violated, and also in OT no CON lonely can do something. They can be effective just in CON hierarchy: a group of CONs with each other, in special hierarchy will be used to choose the best output. The hierarchy of CONs is language specific.

Evaluator: [hereafter EVL] is another functional component in OT which by means of foregoing CONs (language specific hierarchies of CONs) penalizes all the CANs except the one who has violated fewest CONs. In the other words this CAN satisfies the EVL.

Output: is simply the CAN that has been selected by EVL, and the OT presents it as optimal output or surface representation. 
In OT regularly all the CONs and CANs are shown in a special tablue and any CANs violation from any CON will be fined, and the penalty symbol of * will be shown in its sell, and also the optimal CAN will be differentiated by the symbol of

\section{Metathesis in Kalhori}

Kalhori is a geographical variety of Kurdish language which is spoken in southeastern part of the realm of Kurdish, that is located in the borders of Iran and Iraq. The number of its speakers may be about 2 to 3 million.

The data that has been collected for this research shows that the level of occurrence of metathesis among loanwords is significantly more than words originally from Kalhori. In fact occurrence of this process among original Kalhori words is rare, but many of the loanwords that have been entered this dialect of Kurdish language in recent centuries have been the subject of performance of a number of phonological processes to adjust themselves with the Kalhori phonotactic rules. One of these processes that has optimized many of these loanwords is Metathesis. In this paper four kind of metathesis will be presented: the shift of two adjacent consonants in final consonant cluster (contiguous), the shift of two adjacent consonant in the coda and onset of two sequencing syllable (contiguous), the shift of two consonants in the positions of onset and coda of one syllable (non-contiguous) and also the shift of two consonants from two nonadjacent syllable (non-contiguous). This paper will explain the first three kinds through OT, and also at the end of the paper some examples of the occurrence of the fourth kind will be presented.

\section{Contiguous Consonant Cluster Metathesis}

In the following table, some of the samples of reordering of consonants in final consonant cluster have been shown in (1).

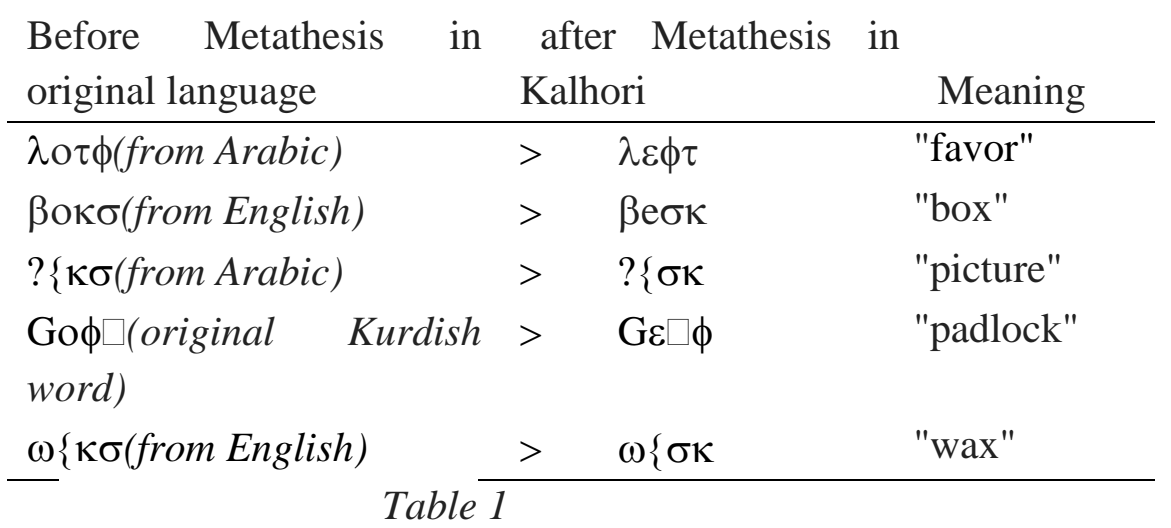

Phonotactic rules of Kalhori don't allow the upper segments sequences to enter the language, and forced them to rearrange themselves, why? A closely observation of all the possible final consonant clusters of the mentioned variety demonstrates that some special sequences are absent, it means that there isn't any one of these consonant sequences among 
other Kalhori syllables. It reveals that phonotactic rules of Kalhori don't accept them. Some sequences like $\mathrm{CV}\left[\mathrm{C}_{+} \text {Plosive } \mathrm{C}_{+ \text {Fricative }}\right]^{*}$ or $\mathrm{CV}\left[\mathrm{C}_{+ \text {Fricative }} \mathrm{C}_{+ \text {Liquid }}\right]^{*}$ are completely unfavored.

According to the SSP principle (that has been introduced in the introduction section) the steepness of the syllable sonority must be from the peak of the syllable toward the edges. Considering the above samples, shows that all of them don't respect the SSP principle. Fery and Vijver (2003: 359) define and formulate SSP as a positive markedness CON as follow: "in a syllable, sonority increases toward the peak and decreases toward the margins". They also formulate following markedness CONs as SSP negative correspondent constraints:

- *PLATEAU- Sonority plateau are disallowed.

- $\quad$ *REVERSAL- Sonority reversal are disallowed.

The markedness CON * REVERSAL emphasized on the sonority based arrangement of the syllable as it has been explained by SSP.

As it has been noticed that faithfulness CONs are totally against any change from input to output. Lacy (2007: 14) defines the faithfulness CON of linear order as follow:

- LINEARITY "for every pair of input segments $x, y$ and their output correspondents $x^{\prime}, y^{\prime}$, incur a violation if $x$ precedes $y$ and $y^{\prime}$ preceds $x^{\prime}$." (No metathesis)

which means, that the given segments sequence of output should be consistent with the input, and vice versa. Clearly it bans metathesis. In OT the conflicts of the CONs is unavoidable. In fact this conflict is a fundamental concept in the theory. As it can be understood from the above faithfulness and markedness CONs, they militate in opposite directions, but what guarantees the optimal output is the language specific hierarchy of the CONs, which means the higher the rank of a CON, the deadlier is the penalty of violation of that CON.

Following tableau shows the optimal forms (considering the original word form in the source language) in Kalhori. Kalhori's specific hierarchy has also been shown in this tableau (1):

Kalhori specific hierarchy: *REVERSAL >> LINEARITY

\begin{tabular}{|l|l|l|}
\hline$\beta \mathrm{o} / \kappa \sigma /$ & $\begin{array}{l}\text { REVERSAL } \\
(\mathrm{SSP})\end{array}$ & LINEARITY \\
\hline$\beta о \kappa \sigma$ & $* !$ & \\
\hline$\beta \mathrm{e} \sigma \kappa$ & & $*$ \\
\hline tableau $(1)$ & \multicolumn{2}{|l}{}
\end{tabular}

It should be noted that in the above hierarchy and tableau some other CONs can be entered, but because they have no effective role in the election of the optimal output, they have been omitted. The first CAN has been fined by the *REVERSAL CON, this means that the CAN didn't satisfied the mentioned CON, because its structure did not respect the SSP constraints. As it has been discussed in the introduction of the paper, stop consonants are less 
sonorant than fricative consonants. A stop consonant should not be placed between a fricative consonant and peak of the syllable. So *REVERSAL CON which don't accept any wrong direction steepness penalizes it, and because, this $\mathrm{CON}$ is the higher ranked CON, the penalty is deadly and other CAN is selected as optimal one.

Contiguous Consonant Metathesis: (in the border of adjacent syllables)

There is also another kind of metathesis in Kalhoris dialect of Kurdish language, in which the final consonant of first syllable and the first consonant of the second syllable change their places with each other. The followings are some samples of this kind of metathesis:

\begin{tabular}{llll}
$\begin{array}{l}\text { Before Metathesis } \\
\text { original language }\end{array}$ & in & $\begin{array}{l}\text { after Metathesis } \\
\text { Kalhori }\end{array}$ & in meaning \\
\hline$\omega \mathrm{A} \kappa+\sigma \varepsilon \nu$ & $>$ & $\omega \mathrm{A} \sigma+\kappa \varepsilon \nu$ & vaccine \\
$? \varepsilon \kappa+\sigma \mathrm{t}+\mathrm{Z} \varepsilon \nu$ & $>$ & $? \varepsilon \sigma+\kappa \imath+\mathrm{Z} \varepsilon \nu$ & $\begin{array}{l}\text { oxygen } \\
\text { taxi }\end{array}$ \\
$\tau \mathrm{A} \kappa+\sigma \mathrm{\imath}$ & $>$ & $\tau \mathrm{A} \sigma+\kappa \mathrm{r}$ &
\end{tabular}

In this group also the main cause of occurrence of metathesis is the SSP principle. As it has been pointed out, the Syllable Contact Law which "holds that the preferred contact between consecutive syllables is one in which the end of the first syllable is higher in sonority than the beginning of the second" (Kingston and Beckman, 1990: 319) can be one of the driving factors of the metathesis. Syllable Contact Law is a universal preference, and Kurdish Kalhori consider this preference as a vital and an important one, so the grammar of this language variety don't permit dispreferred forms to form or to enter the language.

The first syllable of all the above mentioned samples have a stop consonant in the final position of coda, and the subsequent syllables have a fricative (which are more sonorant than the stops) consonant in the first positions of their onsets. They have a marked structure. The markedness CON of Syllable Contact Law is defined by Lopez and Cameron (2003: 47) as follow:

SYLLCON - the onset of a syllable must not be of greater sonority than the last segment in the immediately preceding syllable.

This CON requires that the disprefferred consonant strings in syllable boundaries of the above words to be optimized. But it may be said that there are many other ways to optimize these strings, for instance, deletion of one of the segments or any other process also can be useful. But the faithfulness CONs of MAX require every consonant or vowel of the input form to be preserved in the output (Kar, 2010: 108), they can be formulated and defined as follow:

MAX-IO-C 
[+con] sounds in the input must have output correspondences.

MAX-IO-V

[-con] sounds in the input must have output correspondences.

Which in this paper both of them can be abbreviated as MAX (segments in the input must have output correspondences). Tableau (2) demonstrates the conflict of CONs to choose the optimal form based on language specific hierarchy of CONs:

Table 2. Kalhori specific hierarchy: SYLLCON >> MAX >> LINEARITY

\begin{tabular}{|l|l|l|l|}
\hline$\omega A \kappa+\sigma\{v$ & SYLLCON & MAX & LINEARITY \\
\hline$\omega A+\sigma\{v$ & & $* !$ & \\
\hline$\varpi \omega A \sigma+\kappa\{v$ & & & $* * !$ \\
\hline$\omega A \kappa+\sigma\{v$ & $* !$ & & \\
\hline
\end{tabular}

Metathesized candidate of / $\omega A \sigma . \kappa\{v /$ satisfies the Constraints hierarchy, because it has the fewest violations and therefore receives the fewest penalty.

Non-Contiguous Consonant Metathesis: in one syllable

There are also some instances of non-contiguous metathesis in Kalhori, but the number and also frequency of them is to some extent rare. Totally, occurrence of noncontiguous metathesis is less regular and less systematic than the contiguous type. Nevertheless, these instances will be discussed. The first one is the occurrence of metathesis in a original Kalhori's word of:

$$
\xi\{.4\{. \mathrm{N} \varepsilon \zeta \rightarrow \xi\{.4\{. \zeta \varepsilon \mathrm{N} \quad \text { "red wasp" }
$$

The segment sequence of final syllable in the above word, [.N $\mathrm{N} \zeta]$ has been reordered to /. $\zeta_{\varepsilon N} /$. It seems that this word is the only sample of this type of metathesis in Kalhori. Even though the unmetathesized form [.N $\varepsilon \zeta$ ] is also in some limited areas can be heard, but the metathesized form is dominant, and the majority of the speakers of the mentioned variety of Kurdish language consider the unmetathesized form as an ill-form word. Also, it should be noted that some special speakers pronounce it in the form of $[\xi\{.4\{v . \zeta \varepsilon \gamma]$. it seem that the $[\xi\{.4\{. \mathrm{N} \varepsilon \zeta]$ is an old form of the word in a period of time under the performance of the phonological process of metathesis has been changed. The language variety of Kurdish Kalhori has no standard form, may the presence of two outputs (even though one of them is used widely and the other is not privileged) for one input can be explained through the absence of a standard variety in Kalhori. The most important thing is that, in the second surface representation $([\xi\{.4\{v . \zeta \varepsilon \gamma])$, at first, the process of metathesis has occurred, and after that some of the features of the last consonant $[\mathrm{N}]$ have been changed and another phonological process (epenthesis) entered another segment $[\mathrm{n}]$ into the string of segments. But 
because this process is not the subject of the present paper, we don't continue to speak about that.

Even though there isn't another sample of this kind of metathesis in Kalhori, but the optimality of this structure, concerning the principles of universal grammar and also the general tendency of the grammar of Kurdish Kalhori to coordinate with SSP, can be examined.

According to the sonority cycle which states "within a syllable a large sonority jump is preferred between onset and nucleus, while the preferred or , least marked, sonority profile from the nucleus on is one of little or no decrease in sonority (Coulter, 2014: 50), this instance of metathesis can be explained. The following constraints are the sonority cycle correspondent markedness constraints:

BestCoda Align [+son]: all sonorants to be at the coda.

BestOnset Align [-son]: all obstruents to be at the onset.

after reciting these constraints from (Ito and Mester, 1999), Urbancyzk (2001: 108) adapt these two constraints in a single constraint of SyllCon, but it should be noted that this constraint is different from the one in the preceding tableau, even though the names of them are alike.

Also the principle of correspondence has been defined by McCarthy and Prince (1995: 262) as follow:

Given two strings $S_{1}$ and $S_{2}$, correspondence is the relation $\mathbf{R}$ from the elements of $S_{1}$ to those of $S_{2}$. Elements $\alpha$ (an element of an input string of $S_{1}$ ) and $\beta$ (an element of an input string of $S_{2}$ ) are referred to as correspondents of one another when $\alpha \mathbf{R} \beta$.

Hermans and Oostendrop (2000: 214) formulated some faithfulness constraints, based on the above relation:

\section{DEPENDENCE}

Every element of $\mathrm{S}_{2}$ has a correspondent in $\mathrm{S}_{1}$. [No Deletion]

MAXIMALITY

Every element of $\mathrm{S}_{1}$ has a correspondent in $\mathrm{S}_{2}$. [No Epenthesis]

$\operatorname{IDENTITY}(\gamma \mathrm{F})$

Let $\alpha$ be a segment in $S_{1}$ and $\beta$ be a correspondent of $\alpha$ in $S_{2}$, if $\alpha$ is $[\gamma F]$, then $\beta$ is $[\gamma \mathrm{F}]$. [No Segmental Feature Change]

The second constraint (MAXIMALITY) (which means maximum segments number of the output should be equals with the number of them in Input) can be used in the following hierarchy of constraints to show the preferred and optimal form of output in Kalhori, in which, as it has been pointed out, alongside the optimal form, in some restricted areas some other forms of the output can also be heard. 
In table (3) the optimality of the metathesized form based on the language specific hierarchy has been showed:

Table 3. Language specific hierarchy: SYLLCON $>>$ MAXIMALITY $>>$ LINEARITY

\begin{tabular}{|l|l|l|l|l|}
\hline$\xi\{.4\{. N \varepsilon \zeta$ & SyllCon & MAXIMALITY & LINEARITY & IDENTITY $(\gamma \mathrm{F})$ \\
\hline$\xi\{.4\{. \mathrm{N} \varepsilon \zeta$ & $!^{*}$ & & & \\
\hline$\xi \xi\{.4\{. \zeta \varepsilon \mathrm{N}$ & & & $* *$ & $*$ \\
\hline$\xi\{.4\{v . \zeta \varepsilon \gamma$ & & $* !$ & $*$ & $*$ \\
\hline
\end{tabular}

In the above table, the $\mathrm{CAN}[\xi\{.4\{. \zeta \varepsilon N]$ satisfies the constraint hierarchy and therefore is elected as preferred output form by evaluator. As it has been noticed, there is another form of this word that can be heard in some restricted groups or speakers, $[\xi\{.4\{v . \zeta \varepsilon \gamma]$, even though this form has also fulfilled the constraint of SyllCon, it has not selected by the evaluator, because it violates another low ranked constraints of MAXIMALITY, which forbids epenthesis. This form, even though, is not as the first one preferred, and as it has fulfilled the requirements of SSP and specially Sonority Cycle, as an exception can be present like a alternative form in the language.

\section{Non-Contiguous Consonant Metathesis: over non-adjacent syllables}

The last type of metathesis in Kalhori is a very rare kind of long distance metathesis in which two consonants from two non-adjacent syllable switch places with each other. Even though the occurrence of this type is not very regular, but there are some straight instances of it. All of these instances are also among loanwords. Two of them which have occurred in similar contexts are presented below:

Before Metathesis in original after Metathesis in Kalhori meaning
language

$\beta \cup \lambda . \delta \mathrm{O} . \zeta \cong 4 \quad$ (from English) $>\beta \cup 4 . \delta \mathrm{I} . \zeta \varepsilon \lambda$
$\beta \mathrm{O} \lambda . \beta \varepsilon .4 \mathrm{\imath} \gamma$ (from English) $>\beta \cup 4 . \beta \varepsilon . \lambda \mathrm{\imath N}$

Firstly, some general features of these two instances should be noted [the input words]. Both of them are simple words. Both of them composed of three syllables. Concerning the SSP an SCL, all the syllables in both of them and also the relations between the syllables in syllable boundaries, are preferred and optimal. So it can be said that there isn't any problem with the structure of the syllable from the prospective of sonority and syllable structure well-formedness. It is clear that the reason of occurrence of this process is something beyond the structure of one syllable or even the relations of two adjacent syllable. But why 
they have been metathesized? To find the answer of this question is not so easy, firstly, because this kind of metathesis is rare, therefore it seems that there isn't enough understanding about it in the literature of linguistics, secondly, there aren't enough samples of this kind of metathesis in Kalhori or other varieties of Kurdish language to enable the linguists to find a systematic rule in its performance. The only thing is that there isn't any other three syllabic simple word in Kalhori which have the following structure: $\left[\mathrm{CV}_{[+\mathrm{V},+ \text { back, }}\right.$ +round] $\left.\mathrm{C}_{\lambda / \square} \cdot \mathrm{CV}(\mathrm{C}) \cdot \mathrm{C}_{\rho / 4} \mathrm{~V}\left(\mathrm{C}_{\rho / 4}\right)\right]$.

\section{CONCLUSION}

It has been pointed out that metathesis serves to rearrange phonologically "marked" structures in a more preferred and more acceptable (unmarked) order. In the present paper, some samples of all possible metathesis types in Kalhori dialect of Kurdish language have been investigated, and it has been approved that in three types of them, the performance of this process in the mentioned Kurdish language variety is completely reasonable, as it serves to fulfill the requirements of sonority sequence principle, which itself is one of the most important universal grammar principles, and also is considered as an important one by Kalhori's phonotactic rules. It militates against marked structures and changes them to unmarked and preferred structures. Occurrence of this process is more regular among loanwords, rather than the original words of the language, because the segmental structures of many of them is not preferred and acceptable.

The fourth kind of metathesis in Kalhori dialect is very rare kind, in which a consonant from the first syllable (of a three syllabic structure) shifts its position with another consonant in the third syllable. There are just two samples of this kind of metathesis in Kurdish Kalhori, due to the paucity of data of this kind of metathesis in the literature of linguistics, it seems that further investigations will be needed to explain this kind of metathesis.

\section{REFERENCES}

Ball, J. Martin, Muller, Nicole \& Rutter, Ben, 2014, Phonology for Communication Disorders, Psychology Press.

Bijankhan, Mahmood, 2009, Phonology: Optimality Theory, Samt.

Brugmann, Kalrl, (1902), Kurze verleichende Grammatik der indogermanichsen Sprachen, Walter de Gruyter.

Chomsky, Noam \& Morris Halle, (1968), The Sound Pattern of English, New York, Harper and Row.

Clements, George N. (1990) The role of the sonority cycle in core syllabification. In: John Kingston and Mary Beckman (eds.) Papers in laboratory phonology I: Between the grammar and physics of speech, 283-333. Cambridge: Cambridge University Press. 
Coulter, R. Geoffrey, 2014, Current Issues in ASL Phonology: Phonetics and Phonology, Volume 3, Academic Press.

Cruttenden, Alen, 2014, Gimson's Pronunciation of English, Routledge.

Crystal, D. (1997). A Dictionary of Linguistics and Phonetics. Oxford: Blackwell.

Crystal, David, 2008, A Dictionary of Linguistics and Phonetics, Sixth Edition, Blackwell Publishing.

Damper, I. Robert, 2012, Data-Driven Techniques in Speech Synthesis, Springer Science \& Business Media.

Féry, Caroline, Vijver, V. de Ruben, 2003, The Syllable in Optimality Theory, Cambridge University Press.

Fingan, Edward, 2014, Language: its Structure and use, Cengage Learning.

Gordon, K. Mattew, 2016, Phonological Typology, Oxford University Press.

Haye, Bruce, Kirchner, Robert \& Steriade, Donca, 2004, Phonetically Based Phonology, Cambridge University Press.

Hermans, Be \& Oostendorp, Van Marc, 2000, The Derivational Residue in Phonological Optimality Theory, John Benjamins Publishing.

Hickey, Raymond, 2014, The Sound Structure of Modern Irish, Walter de Gruyter GmbH \& Co KG

Kar, Somdev, 2010, Syllable Structure of Bangla: An Optimality-Theoretic Approach, Cambridge Scholars Publishing.

Kean, Mary-Louise, 1992: Markedness: an Overview. In international Encyclopedia of Linguistics, William Bright, Oxford University press.

Kingston, John \& Beckman, E. Mary, 1990, Papers in Laboratory Phonology: Volume 1, Between the Grammar and Physics of Speech, Cambridge University Press.

Lacy, de Paul, 2007, The Cambridge Handbook of Phonology, Cambridge University Press

Leslau, Wolf, 1992, Gurage Studies: Collected Articles, Otto Harrassowitz Verlag.

Lopez, Luis \& Cameron, Richard, 2003, A Romance Perspective on Language Knowledge and Use: Selected Papers from the 31st Linguistic Symposium on Romance Languages (LRSL), Chicago, 19-22 April 2001, John Benjamins Publishing.

McCarthy, John and Alan Prince (1995). "Faithfulness and Reduplicative Identity,"UMOP 18:Papers in Optimality Theory, ed. by Jill Beckman, Laura Walsh Dickey, and Suzanne Urbanczyk, 249-384. Amherst, Mass.:GLSA

McCarthy, John, J. 2002: a Thematic Guide to Optimality Theory, Cambridge University Press.

Miglio, G. Viola, 2013, Interactions Between Markedness and Faithfulness Constraints in Vowel Systems, Routledge.

Oostendrop, V. Mark, Ewen, J. Colin, Hume, V. Elizabeth \& Rice, Karen, 2011, The Blackwell Companion to Phonology, 5 Velume Set, John Wiley \& Sons.

Pascoe, Michelle, Stackhaus, Joy \& Wells, Bill, 2006, Persisting Speech Difficulties in Children: Children's Speech and Literacy Difficulties, John Wiley \& Sons.

Paul, I., Phillips, V., Travis, Lisa, 2013, Formal Issus in Austronesian Linguistics, Springer Csience \&Business Media.

Powell, J.V., (1985), An occurrence of Metathes/is in Chumakuan, In Acson, Veneeta Z., \& R. Leed. eds., For Gordon H. Fairbanks. Honolulu: University of Hawaii Press. 
Prince, Alen \& Smolensky, Paul, 1993: Optimality Theory: Constraint Interaction in Generative Grammar.

Selkir, Elizabeth. (1984). "On the Major Class features and Syllable theory",. Language Sound Structure, M. Aronoff and R.Oehrle (eds.) 107-134.Cambridge, MA: MIT Press.

Spencer, A. (1996). Phonology, Oxford: Blackwell

Uchihara, Hiroto, 2016, Tone and Accent in Oklahama Cherokee, Oxford University Press.

Uffmann, Christian, 2007, Vowel Epenthesis in Loanword Adaptation, Walter de Gruyter.

Urbancyzk, Suzanne, 2001, Patterns of Reduplication in Lushootseed, Psychology Press. 